See Article page 591.

\section{Commentary: All gets better in time}

Stephanie L. Mick, MD, and Mario Gaudino, MD

In this issue of the Journal, the Michigan Mitral Research group reports their experience with surgical treatment of rheumatic mitral disease. ${ }^{1}$ The authors considered 180 middle-aged patients (mean age 59 years) undergoing primary isolated mitral repair or replacement, the large preponderance of whom had stenotic valves, from 1997 to 2018. Midway through this period, a modification in approach took place in the direction of more-stringent selection criteria for repair in rheumatic mitral disease based on anterior leaflet assessment.

For roughly the first decade of this experience, the policy was aggressively in favor of repair with $70 \%$ repair rate using, eg, subvalvular debridement, over-commissurotomy extending to the annulus, papillary splitting, secondary chord division, and annuloplasty. Around 2009, the threshold for replacement was lowered, with repair favored only in the setting of anterior leaflet mobility with some translucency. In the following decade or so, the repair rate was $33 \%$. Mitral replacement was with bioprosthetic valves in $89 \%$ of patients and chordal continuity maintained through native chord sparing or Gore-Tex neochord implantation.

So what happened when this center flipped from a 70/30 repair/replacement rate to a $\sim 30 / 70$ rate? The patients in the replacement-predominant era "did better," as captured by a composite end point, experiencing a greater freedom from death, reintervention/reoperation, or severe valve dysfunction.

\footnotetext{
From the Department of Cardiothoracic Surgery, Weill Cornell Medicine, New York, NY.

Disclosures: The authors reported no conflicts of interest.

The Journal policy requires editors and reviewers to disclose conflicts of interest and to decline handling or reviewing manuscripts for which they may have a conflict of interest. The editors and reviewers of this article have no conflicts of interest.

Received for publication April 21, 2020; accepted for publication April 23, 2020; available ahead of print May 1, 2020.

Address for reprints: Mario Gaudino, MD, Department of Cardiothoracic Surgery, Weill Cornell Medicine, 525 East 68th St, New York, NY 10065 (E-mail: mfg9004@med.cornell.edu).

J Thorac Cardiovasc Surg 2022;163:603-4

$0022-5223 / \$ 36.00$

Copyright (c) 2020 by The American Association for Thoracic Surgery

https://doi.org/10.1016/j.jtcvs.2020.04.063
}

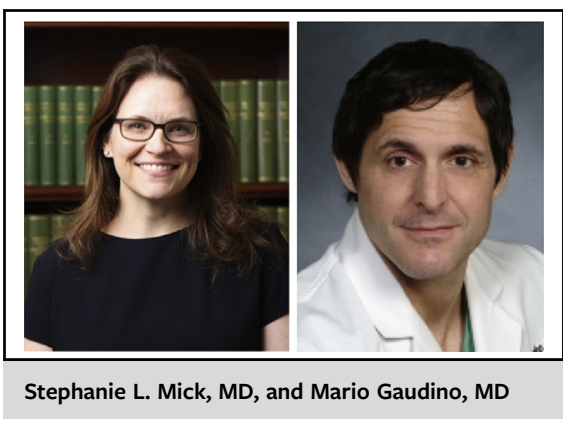

CENTRAL MESSAGE

A lower threshold for replacement appears reasonable in middle-aged patients with rheumatic mitral disease.

The authors' conclusion from the inquiry is that "careful assessment of the anterior leaflet mobility/calcification to determine mitral valve repair or replacement was associated with improved outcomes." From a statistical perspective, however, it is very important to note that the Cox modeling did not show the choice of repair or replacement to have significant relationship to the composite outcome improvement. Moreover, the 5-year cumulative incidence of mitral reoperation did not differ by era and was greater after repair versus replacement $(17 \%$ vs $3.7 \%$, $P=.014)$. Both repair and replacement patients in the second era demonstrated improved survival. Although limited by the shorter duration of follow-up in the second era, there was no suggestion of a survival advantage for mitral valve repair over replacement in this group of rheumatic patients.

With all of this in mind, although there is certainly a clear difference in the composite outcome between the 2 eras, it is not clear that the valve assessment was the main driver of the difference. It is very likely that other factors played important roles, such as an overall improvement of cardiac surgical care in this time period.

That being said, the study does show that middle-aged patients undergoing mitral valve surgery for rheumatic disease did better overall than in the past regardless if replacement or repair was undertaken. Moreover, in the modern era, the patients who received replacements not only enjoyed similar survival but also lower rates of valve reintervention than those undergoing repair. Given these results, along with the fact that current percutaneous reintervention technology yields superior outcomes post 
replacement ${ }^{2-4}$ (when anatomically feasible, ${ }^{5}$ an important caveat) than postrepair, a lower threshold for replacement appears reasonable in middle-aged patients with rheumatic mitral valve disease.

\section{References}

1. Brescia AA, Watt TM, Murray SL, Rosenbloom LM, Kleeman KC, Allgeyer H, et al. Rheumatic mitral valve repair or replacement in the valve-in-valve era. $J$ Thorac Cardiovasc Surg. 2022;163:591-602.e1.

2. Yoon SH, Whisenant BK, Bleiziffer S, Delgado V, Schofer N, Eschenbach L, et al. Transcatheter mitral valve replacement for degenerated bioprosthetic valves and failed annuloplasty rings. J Am Coll Cardiol. 2017;70:1121-31.
3. Guerrero M, Vemulapalli S, Xiang Q, Wang DD, Eleid M, Cabalka AK, et al. Thirty-day outcomes of transcatheter mitral valve replacement for degenerated mitral bioprostheses (valve-in-valve), failed surgical rings (valve-in-ring), and native valve with severe mitral annular calcification (valve-in-mitral annular calcification) in the United States: data from the Society of Thoracic Surgeons/American College of Cardiology/transcatheter valve therapy registry. Circ Cardiovasc Interv. 2020;13:e008425.

4. Grover FL, Vemulapalli S, Carroll JD, Edwards FH, Mack MJ, Thourani VH, et al. 2016 annual report of the Society of Thoracic Surgeons/American College of Cardiology transcatheter valve therapy registry. J Am Coll Cardiol. 2017;69: 1215-30.

5. Yoon SH, Bleiziffer S, Latib A, Eschenbach L, Ancona M, Vincent F, et al. Predictors of left ventricular outflow tract obstruction after transcatheter mitral valve replacement. JACC Cardiovasc Interv. 2019;12:182-93.
See Article page 591.

\section{Commentary: Rheumatic mitral repair: Just don't do it?}

\author{
Patrick M. McCarthy, MD
}

Fortunately, rheumatic disease has greatly decreased in the United States and as noted by Brescia and colleagues ${ }^{1}$ is different here than much of Asia with a preponderance of mitral stenosis (MS) or mixed disease. Of note, it generally occurs later in life as well, and the mean age in this report was $59 \pm 14$ years. The authors focus on the mobility of the anterior leaflet to decide if the mitral valve can be safely repaired, and they became more conservative during the second decade (repair decreased from $70 \%$ to $33 \%$ ). The article compares outcomes in the 2 decades, but a question not addressed is if the success of repair with pure mitral regurgitation (MR) was different than for that with MS or mixed disease. Perhaps the results with pure MR are better and approximate the results outside of the United States that they discuss. If the valve leaflets have begun to calcify, then

From the Northwestern University/Northwestern Memorial Hospital, Chicago, Ill. Disclosures: Dr McCarthy: Edwards Lifesciences: speaking fees and royalties; Medtronic and AtriCure: speaking fees; Abbott: Surgical primary investigator REPAIRMR Trial.

The Journal policy requires editors and reviewers to disclose conflicts of interest and to decline handling or reviewing manuscripts for which they may have a conflict of interest. The editors and reviewers of this article have no conflicts of interest.

Received for publication May 18, 2020; accepted for publication May 18, 2020; available ahead of print June 16, 2020.

Address for reprints: Patrick M. McCarthy, MD, Cardiac Surgery Division, Northwestern Medical Group, 676 North Saint Clair Street Arkes Family Pavilion, Suite 730, Chicago, IL 60611 (E-mail: Patrick.McCarthy@nm.org).

J Thorac Cardiovasc Surg 2022;163:604-5

$0022-5223 / \$ 36.00$

Copyright (c) 2020 by The American Association for Thoracic Surgery

https://doi.org/10.1016/j.jtcvs.2020.05.078
Check for updates

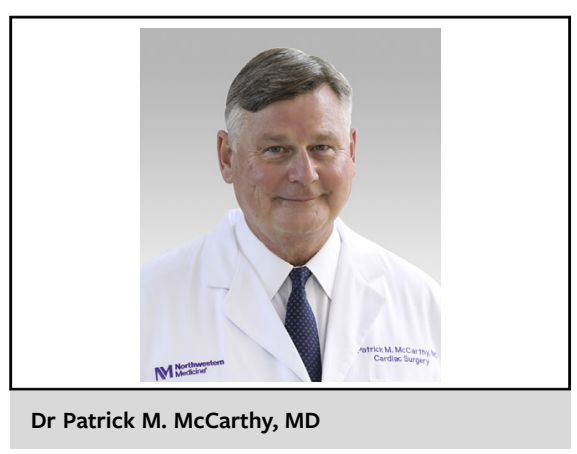

CENTRAL MESSAGE

Early failure after rheumatic

repair is not uncommon. The

Michigan Medicine group

became more cautious over

time, and perhaps a subset of

young patients with pure MR

should be considered for repair.

repair failure due to progressive calcification may be likely. Table 5 reports, for those with a known cause, 7 of 8 failed due to MS or mixed disease. Also, early failure was common. Reoperation was frequently within the first year or less than 5 years in all but 1 patient (who underwent reoperation at 6.5 years). Patient age is an important consideration that is not addressed as clearly as it should be. Bioprosthetic valve freedom from structural valve deterioration at 10 and 15 years is heterogeneous but approximately $84 \%$ to $93 \%$ and $61 \%$ to $81 \%$ depending on the valve type. ${ }^{2}$ What lessons does this hold for the third decade? Mitral reoperation for bioprosthetic structural 